\title{
Outcomes of Percutaneous Coronary Intervention in Patients with Crohn's Disease and Ulcerative Colitis (from a nationwide cohort)
}

Running title: PCI in patients with IBD

Ofer Kobo, MD MHA ${ }^{1 *}$, Mohamed O. Mohamed, MRCP(UK) ${ }^{2,3^{*}}$, Adam D Farmer, $\mathrm{PhD}^{4}, \mathrm{M}$ Chadi Alraies, $\mathrm{MD}^{5}$, Tejas Patel, $\mathrm{MD}^{6}$, Kamal Sharma, $\mathrm{MD}^{6}$, Jim Nolan, $\mathrm{MD}^{2,3}$, Rodrigo Bagur, $\mathrm{MD}^{2}$, Ariel Roguin, MD PhD ${ }^{1,7}$, Mamas A. Mamas, DPhil ${ }^{2,3,8}$

*Equal contribution status - joint first authors

1. Department of Cardiology, Hillel Yaffe Medical Center, Hadera, Israel.

2. Keele Cardiovascular Research Group, Centre for Prognosis Research, Institutes of Applied Clinical Science and Primary Care and Health Sciences, Keele University, United Kingdom

3. Department of Cardiology, Royal Stoke University Hospital, Stoke-on-Trent, United Kingdom

4. Department of Gastroenterology, Royal Stoke University Hospital, Stoke-on-Trent, United Kingdom

5. Wayne State University, Detroit Medical Center, Detroit, Michigan, United States

6. U.N.Mehta ICRC, B.J.Medical college, Ahmedabad, India

7. Rappaport - Faculty of Medicine, Technion - Israel Institute of Technology, Israel.

8. Department of Cardiology, Jefferson University, Philadelphia, USA

\section{Correspondence to:}

Mamas A. Mamas

Professor of Cardiology

Keele Cardiovascular Research Group,

Centre for Prognosis Research,

Institute for Primary Care and Health Sciences,

Keele University, UK.

mamasmamas1@yahoo.co.uk

Word count: 3566 


\begin{abstract}
Patients with inflammatory bowel disease (IBD) are at an increased risk of ischemic heart disease. However, there is limited evidence on how their outcomes after percutaneous coronary intervention (PCI) compare to those without IBD. All PCI-related hospitalizations from the National Inpatient Sample between 2004 and 2015 were included, stratified into three groups: no-IBD, Crohn's disease (CD) and ulcerative colitis (UC). We assessed the association between IBD subtypes and in-hospital outcomes. A total of 6,689,292 PCI procedures were analyzed, of which $0.3 \%(\mathrm{n}=18,910)$ had an IBD diagnosis. The prevalence of IBD increased from $0.2 \%$ (2004) to $0.4 \%$ (2015). Patients with IBD were less likely to have conventional cardiovascular risk factors and more likely to undergo PCI for an acute indication, and to receive bare metal stents. In comparison to patients without IBD, those with IBD had reduced or similar adjusted odds ratios (OR) of MACCE (CD: OR 0.69, 95\% confidence interval (CI) 0.62-0.78; UC: OR 0.75, 95\%CI 0.66-0.85), mortality (CD: OR 0.94, 95\%CI 0.79-1.11; UC: OR 0.35, 95\%CI 0.27-0.45) or acute CVA (CD: OR 0.73, 95\%CI 0.60-0.89; UC: OR 0.94, 95\%CI 0.77-1.15). However, IBD patients had an increased odds for major bleeding (CD: OR 1.42 95\%CI 1.23-1.63 and UC: OR 1.35 95\%CI 1.16-1.58). In summary, IBD is associated with a decreased risk of in-hospital post-PCI complications other than major bleeding that was significantly higher in this group. Long term follow-up is required to evaluate the safety of PCI in IBD patients from both bleeding and ischemic perspectives.
\end{abstract}

Key Words: Percutaneous coronary intervention, inflammatory bowel disease, Crohn's disease, ulcerative colitis, outcomes 


\section{Introduction:}

Inflammatory bowel diseases (IBD), including Crohn's disease (CD) and ulcerative colitis (UC), are chronic inflammatory conditions with an estimated global prevalence of 0.2$0.8 \%{ }^{1,2}$. While their manifestations are mainly gastrointestinal, they are frequently associated with cardiovascular conditions such as atrial fibrillation (AF), heart failure, as well as ischemic heart disease $(\mathrm{IHD})^{3-6}$. The latter is primarily attributed to the autoinflammatory pathogenesis of IBD as well as some of its associated treatments such as corticosteroids, which promote atherogenesis and enhance the risk of IHD. ${ }^{7-10}$ Despite previous reports of worse PCI-related outcomes with some chronic inflammatory conditions, there is limited evidence on procedural outcomes of PCI in patients with IBD. ${ }^{11-15}$ we examined the prevalence of IBD, their clinic al characteristics and in-hospital outcomes in patients undergoing PCI from a nationally representative sample in the United States (US).

\section{Methods:}

The National Inpatient Sample (NIS) is the largest all-payer inpatient health care database in the United States developed by the Healthcare Cost and Utilization Project (HCUP) and sponsored by the Agency for Healthcare Research and Quality (AHRQ). ${ }^{16,17}$ The NIS dataset contains hospital information on between 7 and 8 million yearly hospital discharges from 2004 onwards. Since 2012, the NIS samples discharge from all hospitals participating in HUCP, approximating a 20\% stratified sample of all discharges from US community hospitals. The sampling strategy has changed over time in order to produce more generalizable estimates by reducing sampling bias. Before 2012 the NIS retained all discharges, but only from a sample of hospitals. 
All patients underwent PCI from January 2004 through September 2015 were included, identified using the following International Classification of Diseases, Ninth Revision, Clinic al Modification (ICD-9-CM) procedure codes: 00.66, 36.06, 36.07, 36.01, 36.02, and 36.05.

All records were eligible for inclusion if discharge record showed that the patient had undergone a PCI procedure during their hospital stay and was over the age of 18 years. Information on patient demographics were recorded for each hospital discharge including age, gender, race, admission type (elective or emergent), admission day (weekday or weekend), expected primary payer and median household income according to ZIP code. Missing records for age, gender, elective or weekend admission and hospital location/ teaching status were excluded from the analysis. Patients with known primary connective tissue disease were also excluded from analysis. Each discharge record had information on up to 30 diagnoses (15 between 2004 and 2008, 25 between 2009 and 2013, and 30 in 2014). A full list of ICD 9-CM codes used to identify CD (555.x), UC (556.x), as well as other patient characteristics and complications is provided in Supplementary Table 1. ICD 9-CM codes were also used to identify procedural information including multi-vessel vs. single-vessel procedure, bifurcation lesions, type of stent type deployed (bare metal (BMS) or drug eluting (DES)), use of adjunctive devices including intracoronary pressure wire, intravascular ultrasound (IVUS), Optical Coherence Tomography (OCT), assist device or intra-aortic balloon pump (IABP).

The main outcome was to compare the in-hospital clinical outcomes, including major adverse cardiovascular and cerebrovascular events (MACCE) (composite of mortality, acute stroke or transient ischemic attack (TIA) and cardiac complications), all-cause mortality and major bleeding, between patients with and without IBD. Cardiac complications included coronary dissection, pericardial effusion or hemopericardium and cardiac tamponade. Major bleeding events were defined as a composite of diagnosis of gastrointestinal, retroperitoneal, 
intracranial, intracerebral hemorrhage, unspecified hemorrhage, and whether a blood transfusion was required.

Statistical analysis was performed on IBM SPSS version 25. Continuous variables are presented as median and interquartile range, due to skewed data, and categorical data are presented as frequencies and percentages. Missing data were assumed to be missing at random. For all analyses, cases were weighted. The use of sampling weights was required because the design of the study means that different observations may have different probabilities of selection. Sampling weights for each individual discharge that were provided by the AHRQ were used.

Multivariable logistic regression models were to examine the association between IBD and its subtypes to in-hospital complications. All models were adjusted for potential confounders. These included age, gender, elective admission, weekend admission, hospital location/teaching status, type of clinical syndrome (ST elevation myocardial infarction (STEMI), non-STEMI (NSTEMI), unstable or stable angina), cardiogenic shock, use of assist device/IABP, diabetes, hypertension, dyslipidaemia, renal failure, thrombocytopenia, coagulopathy, anaemia, chronic liver and lung diseases, smoking status, malignancy, previous bowel resection, known ischaemic heart disease or heart failure, previous myocardial infarction (MI) or cerebrovascular accident (CVA), multi-vessel PCI and type of stent (drug eluting (DES) or bare metal (BMS)).

\section{Results}

A total of 6,689,292 PCI procedures were recorded between 2004 and 2015, of which 18,910 patients $(0.28 \%)$ had a diagnosis of IBD. The number of patients with CD and UC were $10,367(0.15 \%)$ and 8,543 (0.13\%), respectively. Between 2004 and 2015, the rate of IBD amongst all those undergoing PCI doubled from $0.2 \%$ to $0.4 \%$. 
In comparison to those without IBD, patients with $\mathrm{CD}$ were younger and more likely to be female whereas those with UC were more likely to be male. (Table 1) Patients with IBD were more likely to be white and had a lower prevalence of certain conditions such as heart failure, diabetes, peripheral vascular disease and previous history of CVA, MI or coronary revascularization (PCI or CABG). In contrast, IBD patients had a higher prevalence of $\mathrm{AF}$, malignancies (solid tumors and metastatic disease), bleeding diatheses (anemia, thrombocytopenia, coagulopathy), and chronic liver disease.

Patients with IBD were more likely to undergo PCI for an acute indication (STEMI and NSTEMI) compared to those without IBD. (Table 1) The rates of single vessel PCI and BMS use were higher in the IBD groups. The median length of stay was similar in all groups, while the cost of admission for patients with UC was higher than CD or non-IBD patients. (Table 1) Between 2004-2015 the rates of BMS decreased from $23 \%$ to $14 \%$.

Overall, the crude rates of in-hospital MACCE, mortality acute stroke/TIA and vascular complication were lower in UC and CD patients compared to non-IBD patients. (Table 2, Figure 2) However, in comparison to non-IBD patients, the rates of cardiac complications were lower in CD patients and higher in UC patients. In multivariable analysis, patients with UC and CD had reduced odds of MACCE (CD: OR 0.69, 95\% CI 0.62-0.78; UC: OR 0.75, 95\% CI 0.66-0.85), mortality (CD: OR 0.94, 95\% CI 0.79-1.11; UC: OR 0.35, 95\% CI 0.27-0.45) and acute stroke/TIA (CD: OR 0.73, 95\% CI 0.60-0.89; UC: OR 0.94, 95\% CI 0.77-1.15), compared to those without IBD. (Figure 3)

The crude rates of major bleeding were higher in the IBD groups compared to the nonIBD group, mainly driven by higher rates of GI bleeding in the IBD groups. (Table 2, Figure 2) Patients with CD and UC had an increase in adjusted odds of major bleeding compared to 
those without IBD (CD: OR $1.4295 \%$ CI 1.23-1.63 and UC: OR $1.3595 \%$ CI 1.16-1.58)

(Figure 3)

\section{Discussion}

This is the first national-level analysis comparing procedural outcomes between patients with and without IBD undergoing PCI. First, we show that IBD patients represent a small proportion of those undergoing PCI, although their prevalence has doubled over the study decade. Second, we observe differences in risk profile and indications between patients with and without IBD. Patients with IBD have a lower prevalence of conventional cardiovascular risk factors compared to those without IBD, but also a higher prevalence of risk factors for bleeding. Furthermore, IBD patients were more likely to undergo PCI for ACS than stable angina. After adjustment for differences in risk profile and PCI indication, we find that IBD (UC and CD) was associated with reduced odds for MACCE, mortality and acute CVA, but was independently associated with an increased risk of major bleeding.

Patients with IBD are at a heightened risk of ischemic heart disease, for which they may require coronary revascularization, but little is known about their prevalence amongst patients undergoing PCI, and their clinical outcomes. ${ }^{4}$ Although IBD patients represent a small proportion of those undergoing PCI, their prevalence has doubled over the study period. However, there is limited procedural outcomes data for this population, for example, an analysis of 131 patients with IBD and IHD, of which less than $30 \%$ underwent PCI, demonstrated no difference in overall complications between IBD and non-IBD subjects. ${ }^{15}$

We show that IBD, including CD and UC, was associated with a lower risk of MACCE, mortality, acute stroke and vascular complications. In the absence of established evidence on PCI outcomes in this group it is difficult to compare our findings to those in previous literature. One previous study found lower mortality among IBD patients admitted with MI. The observed 
differences in the outcomes of UC and CD patients were not previously reported. ${ }^{18}$ Although some factors such as pharmacotherapeutic use and angiographic findings were not adjusted for in our analysis, several reasons could explain why patients with IBD experience lower rates of ischemic and vascular complications. IBD patients are younger and, therefore, less likely to have complex lesions including diffuse atherosclerosis, calcific or multivessel coronary artery disease that are known to be associated with adverse outcomes Our analysis suggests that patients undergoing IBD are at greater risk of sustaining in-hospital major bleeding complications, mainly driven through increased gastrointestinal bleeding events. The latter finding is of great clinical significant since it provides insights in to the inherent bleeding risk in this patient group, who are currently not considered in high-bleeding risk definitions. ${ }^{19} \mathrm{We}$ observe higher rates of BMS use in IBD patients, which could be explained by physicians' recognition of the potential higher risk of long-term bleeding in this group and their possibility of early discontinuation of dual antiplatelet therapy. ${ }^{20-22}$ However, BMS have been shown to be inferior to DES in the long-term with respect to outcomes such as target lesion and vessel revascularization and risk of reinfarction. ${ }^{23}$ In the recent years, as an alternative to BMS in high bleeding risk groups, many studies reported favorable outcomes of new stent platforms, as well as new antiplatelet therapy strategies with shorter DAPT duration. The adoption of such may help to reduce the higher bleeding risk in this group. ${ }^{24-26}$ Furthermore, use of less potent antiplatelet agents may serve to decrease the bleeding risk further.

The are several limitations to the present study. First, the NIS is an administrative dataset, and coding error may be a source of bias. The identification of PCI and IBD diagnoses as well as other comorbidities and procedural data was based on the use of administrative codes. However, the NIS is a validated database, and the use of ICD-9 codes have been previously validated for the purposes of cardiovascular research. ${ }^{27,28}$ Second, the NIS relate only to inhospital outcomes and therefore longer-term follow-up of mortality and other adverse events 
are missing from our analysis. As IBD are chronic inflammatory conditions, the full extent of the risk related to it may be underestimated on short-term follow- up ${ }^{11,12,29}$ Finally, the NIS database does not include data that may be relevant. It does not include pharmacotherapy; hence we were unable to determine differences in the use of antithrombotic therapy between the study groups or to determine the effect of baseline IBD treatment on clinical outcomes, which may both act as confounders ${ }^{3,8,20}$. The NIS also does not provide certain procedural information such as coronary lesion and procedural complexities, type of DES used (1 $1^{\text {st }}$ vs $2^{\text {nd }}$ generation) and extent of revascularization. Laboratory results, including inflammatory markers, are also not included in the NIS database. Nevertheless, we believe that our findings provide insight into the 'real world' in-hospital clinical outcomes of a large and unselected cohort of patients with inflammatory bowel diseases underwent PCI.

In conclusion, patients with IBD undergoing PCI have increased in prevalence over an eleven-year period. Patients with IBD are less likely to have conventional cardiovascular risk factors and are more likely to undergo PCI for an acute indication. Although this group was associated with a reduced risk of in-hospital mortality, acute stroke and vascular complications after PCI, they were more likely to experience major bleeding, specifically gastrointestinal in origin. The present findings emphasize the importance of incorporating IBD as part of the high bleeding risk criteria when risk-stratifying patients undergoing PCI as well as the need for longterm follow-up studies of post-PCI outcomes this patient group. 


\section{References:}

1. Abraham C, Cho JH. Inflammatory bowel disease. N Engl J Med 2009;361(21):20662078. doi:10.1056/NEJMra0804647

2. Ng SC, Shi HY, Hamidi N, Underwood FE, Tang W, Benchimol EI, Panaccione R, Ghosh S, Wu J, Chan F, Sung J, Kaplan GG. Worldwide incidence and prevalence of inflammatory bowel disease in the 21st century: a systematic review of populationbased studies. Lancet 2017;390(10114):2769-2778. doi:10.1016/S01406736(17)32448-0

3. Aniwan S, Pardi DS, Tremaine WJ, Loftus E V. Increased Risk of Acute Myocardial Infarction and Heart Failure in Patients With Inflammatory Bowel Diseases. Clin Gastroenterol Hepatol 2018;16(10):1607-1615.e1 doi:10.1016/j.cgh.2018.04.031

4. Choi YJ, Lee DH, Shin DW, Han KD, Yoon H, Shin CM, Park YS, Kim N. Patients with inflammatory bowel disease have an increased risk of myocardial infarction: a nationwide study. Aliment Pharmacol Ther 2019;50(7):769-779. doi:10.1111/apt.15446

5. Choi YJ, Choi EK, Han KD, Park J, Moon I, Lee E, Choe WS, Lee SR, Cha MJ, Lim $\mathrm{WH}$, Oh S. Increased risk of atrial fibrillation in patients with inflammatory bowel disease: A nationwide population-based study. World J Gastroenterol 2019;25(22):2788-2798. doi:10.3748/wjg.v25.i22.2788

6. Feng W, Chen G, Cai D, Zhao S, Cheng J, Shen H. Inflammatory Bowel Disease and Risk of Ischemic Heart Disease: An Updated Meta-Analys is of Cohort Studies. J Am Heart Assoc 2017; 6(8):e05892. doi:10.1161/JAHA.117.005892

7. Kirchgesner J, Beaugerie L, Carrat F, Andersen NN, Jess T, Schwarzinger M, BERENICE study group.. Increased risk of acute arterial events in young patients and severely active IBD: a nationwide French cohort study. Gut 2018;67(7):1261-1268. doi:10.1136/gutjnl-2017-314015

8. Kirchgesner J, Nyboe Andersen N, Carrat F, Jess T, Beaugerie L, BERENICE study group. Risk of acute arterial events associated with treatment of inflammatory bowel diseases: nationwide French cohort study. Gut 2020;69(5):852-858. doi: 10.1136/gutjnl-2019-318932. 
9. Le Gall G, Kirchgesner J, Bejaoui M, Landman C, Nion-Larmurier I, Bourrier A, Sokol H, Seksik P, Beaugerie L. Clinical activity is an independent risk factor of ischemic heart and cerebrovascular arterial disease in patients with inflammatory bowel disease. PLoS One 2018;13(8): :e0201991. doi:10.1371/journal.pone.0201991

10. Panico C, Condorelli G. Unmet Needs in the Pathogenesis and Treatment of Cardiovascular Comorbidities in Chronic Inflammatory Diseases. Clin Rev Allergy Immunol 2018;55(3):254-270. doi:10.1007/s12016-017-8624-5

11. Lai CH, Lai WW, Chiou MJ, Lin WC, Yang YJ, Li CY, Tsai LM. Outcomes of percutaneous coronary intervention in patients with rheumatoid arthritis and systemic lupus erythematosus: an 11-year nationwide cohort study. Ann Rheum Dis 2016;75(7):1350-1356. doi:10.1136/annrheumd is-2015-207719

12. Sintek MA, Sparrow CT, Mikuls TR, Lindley KJ, Bach RG, Kurz HI, Novak E, Singh J. Repeat revascularisation outcomes after percutaneous coronary intervention in patients with rheumatoid arthritis. Heart 2016;102(5):363-369. doi:10.1136/heartjnl2015-308634

13. Borovac JA, Kwok CS, Iliescu C, Lee HJ, Kim PY, Palaskas NL, Zaman A, Butler R, Lopez-Mattei JC, Mamas MA. Percutaneous Coronary Intervention and Outcomes in Patients With Lymphoma in the United States (Nationwide Inpatient Sample [NIS] Analysis). Am J Cardiol 2019;124(8):1190-1197. doi:10.1016/j.amjcard.2019.07.015

14. Martinez SC, Mohamed M, Potts J, Abhishek A, Roddy E, Savage M, Bharadwaj A, Kwok CS, Bagur R, Mamas MA. Percutaneous coronary intervention outcomes in patients with rheumatoid arthritis, systemic lupus erythematosus and systemic sclerosis. Rheumatology (Oxford) January 2020:kez639. doi:10.1093/rheumatology/kez639

15. Aggarwal A, Atreja A, Kapadia S, Lopez R, Achkar JP. Conventional risk factors and cardiovascular outcomes of patients with inflammatory bowel disease with confirmed coronary artery disease. Inflamm Bowel Dis 2014;20(9):1593-1601. doi:10.1097/MIB.0000000000000109

16. HCUP National Inpatient Sample (NIS) Healthcare Cost and Utilization Project (HCUP). Agency for Healthcare Research and Quality, Rockville, MD2012 (Available at:). https://www.hcup-us.ahrq.gov/nisoverview.jsp. Accessed January 30, 2020. 
17. Mohamed MO, Rashid M, Farooq S, Siddiqui N, Parwani P, Shiers D, Thamman R, Gulati M, Shoaib A, Chew-Graham C, Mamas MA. Acute Myocardial Infarction in Severe Mental Illness: Prevalence, Clinical Outcomes, and Process of Care in U.S. Hospitalizations. Can J Cardiol 2019;35(7):821-830. doi:10.1016/j.cjca.2019.04.021

18. Ehrenpreis ED, Zhou Y, Alexoff A, Melitas C. Effect of the Diagnosis of Inflammatory Bowel Disease on Risk-Adjusted Mortality in Hospitalized Patients with Acute Myocardial Infarction, Congestive Heart Failure and Pneumonia. Plos one 2016;11(7):e0158926. DOI: 10.1371/journal.pone.0158926.

19. Urban P, Mehran R, Colleran R, Angiolillo DJ, Byrne RA, Capodanno D, Cuisset T, Cutlip D, Eerdmans P, Eikelboom J, Farb A, Gibson CM, Gregson J, Haude M, James SK, Kim HS, Kimura T, Konishi A, Laschinger J, Leon MB, Magee PFA, Mitsutake Y, Mylotte D, Pocock S, Price MJ, Rao SV, Spitzer E, Stockbridge N, Valgimigli M, Varenne O, Windhoevel U, Yeh RW, Krucoff MW, Morice MC. Defining High Bleeding Risk in Patients Undergoing Percutaneous Coronary Intervention. Circulation 2019;140(3):240-261. doi:10.1161/CIRCULATIONAHA.119.040167

20. Pepe M, Cecere A, D'Alessandro P, Fumarola F, Ciccone MM, Marchese A, Guaricci AI, Giordano A, Bortone AS, Favale S. Massive stent thrombosis during active ulcerative colitis: the tricky balance between manifest hemorrhagic and concealed thrombotic risk. Clin Exp Med 2018;18(4):481-485. doi:10.1007/s10238-018-0522-5

21. Yazıcı HU, Birdane A, Nadiradze A, Ünalir A. Late bare-metal stent thrombosis in a patient with Crohn's disease. Anadolu Kardiyol Derg 2011;11(5):462-464. doi:10.5152/akd.2011.117

22. Kaiser C, Galatius S, Jeger R, Gilgen N, Skov Jensen J, Naber C, Alber H, Wanitschek M, Eberli F, Kurz DJ, Pedrazzini G, Moccetti T, Rickli H, Weilenmann D, Vuillomenet A, Steiner M, Von Felten S, Vogt DR, Wadt Hansen K, Rickenbacher P, Conen D, Müller C, Buser P, Hoffmann A, Pfisterer M; BASKET-PROVE II study group. Long-term efficacy and safety of biodegradable-polymer biolimus-eluting stents : Main results of the basel stent kosten-effektivitäts trial-prospective validation examination II (BASKET-PROVE II), A randomized, controlled noninferiority 2-year outcome tri. Circulation 2015;131(1):74-81. doi:10.1161/CIRCULATIONAHA.114.013520 
23. Madhavan MV, Kirtane AJ, Redfors B, Généreux P, Ben-Yehuda O, Palmerini T, Benedetto U, Biondi-Zoccai G, Smits PC, von Birgelen C, Mehran R, McAndrew T, Serruys PW, Leon MB, Pocock SJ, Stone GW. Stent-Related Adverse Events >1 Year After Percutaneous Coronary Intervention. J Am Coll Cardiol 2020;75(6):590-604. doi:10.1016/j.jacc.2019.11.058

24. Garot P, Morice MC, Tresukosol D, Pocock SJ, Meredith IT, Abizaid A, Carrié D, Naber C, Iñiguez A, Talwar S, Menown IBA, Christiansen EH, Gregson J, Copt S, Hovasse T, Lurz P, Maillard L, Krackhardt F, Ong P, Byrne J, Redwood S, Windhövel U, Greene S, Stoll HP, Urban P; LEADERS FREE Investigators. 2-Year Outcomes of High Bleeding Risk Patients After Polymer-Free Drug-Coated Stents. J Am Coll Cardiol 2017;69(2):162-171. doi:10.1016/j.jacc.2016.10.009

25. Watanabe H, Domei T, Morimoto T, Natsuaki M, Shiomi H, Toyota T, Ohya M, Suwa S, Takagi K, Nanasato M, Hata Y, Yagi M, Suematsu N, Yokomatsu T, Takamisawa I, Doi M, Noda T, Okayama H, Seino Y, Tada T, Sakamoto H, Hibi K, Abe M, Kawai K, Nakao K, Ando K, Tanabe K, Ikari Y, Hanaoka KI, Morino Y, Kozuma K, Kadota K, Furukawa Y, Nakagawa Y, Kimura T; STOPDAPT-2 Investigators. Effect of 1-Month Dual Antiplatelet Therapy Followed by Clopidogrel vs 12-Month Dual Antiplatelet Therapy on Cardiovascular and Bleeding Events in Patients Receiving PCI: The STOPDAPT-2 Randomized Clinical Trial. JAMA 2019 Jun 25;321(24):2414-2427. doi: 10.1001/jama.2019.8145. PMID: 31237644; PMCID: PMC6593641.

26. Kedhi E, Latib A, Abizaid A, Kandzari D, Kirtane AJ, Mehran R, Price MJ, Simon D, Worthley S, Zaman A, Brar S, Liu M, Stone GW, Windecker S. Rationale and design of the Onyx ONE global randomized trial: A randomized controlled trial of highbleeding risk patients after stent placement with 1 month of dual antiplatelet therapy. Am Heart J. 2019 Aug;214:134-141. doi: 10.1016/j.ahj.2019.04.017. Epub 2019 May 6. PMID: 31203158.

27. Birman-Deych E, Waterman AD, Yan Y, Nilasena DS, Radford MJ, Gage BF. Accuracy of ICD-9-CM codes for identifying cardiovascular and stroke risk factors. Med Care 2005;43(5):480-485. doi:10.1097/01.mlr.0000160417.39497.a9

28. DeShazo JP, Hoffman MA. A comparison of a multistate inpatient EHR database to the HCUP Nationwide Inpatient Sample. BMC Health Serv Res 2015;15:384. doi:10.1186/s12913-015-1025-7 
29. Spartera M, Godino C, Baldissera E, et al. Long-term clinical outcomes of patients with rheumatoid arthritis and concomitant coronary artery disease. Am J Cardiovasc Dis 2017;7(1):9-18.

http:/www.ncbi.nlm.nih.gov/pubmed/28337386\%0Ahttp://www.pubmedcentral.nih.g ov/articlerender.fcgi?artid=PMC5344967. 


\section{Figures legend:}

Figure 1. Flow diagram of study population.

Legend: PCI: percutaneous coronary intervention; NIS: National Inpatient Sample; ICD-9: International Classification of Diseases, Ninth Revision, Clinical Modification

Figure 2. Crude rates of in-hospital outcomes.

Legend: IBD: Inflammatory Bowel Disease; CD: Crohn's Disease; UC: ulcerative colitis Figure 3. Adjusted odds ratios (OR) of in-hospital adverse outcomes*

Legend: *reference group: patients without IBD; CD: Crohn's Disease; UC: ulcerative colitis 
Table 1: Patients' demographics and procedural characteristics for included hospital records, stratified by a diagnosis

\begin{tabular}{|c|c|c|c|c|}
\hline Patient Characteristics & $\begin{array}{c}\text { No IBD } \\
(n=6,670,383)\end{array}$ & $\begin{array}{c}C D \\
(n=10,367)\end{array}$ & $\begin{array}{c}\mathrm{UC} \\
(\mathrm{n}=8,543)\end{array}$ & P Value \\
\hline Age (years), median (IQR) & $65(56,74)$ & $63(55,72)$ & $65(58,74)$ & $<0.001$ \\
\hline Women & $33.2 \%$ & $39.8 \%$ & $30.6 \%$ & $<0.001$ \\
\hline Ethnicity & & & & \multirow[t]{7}{*}{$<0.001$} \\
\hline White & $79 \%$ & $89.3 \%$ & $89.5 \%$ & \\
\hline Black & $8.2 \%$ & $4.9 \%$ & $3.7 \%$ & \\
\hline Hispanic & $6.6 \%$ & $2.6 \%$ & $2.6 \%$ & \\
\hline Asian/Pacific Islander & $2 \%$ & $0.5 \%$ & $0.9 \%$ & \\
\hline Native American & $0.5 \%$ & $0.5 \%$ & $0.1 \%$ & \\
\hline Other & $3.6 \%$ & $2.1 \%$ & $3.3 \%$ & \\
\hline Hospital Location & & & & \multirow[t]{5}{*}{$<0.001$} \\
\hline Northeast & $8.5 \%$ & $11.8 \%$ & $15.1 \%$ & \\
\hline Midwest & $30.8 \%$ & $34.8 \%$ & $36.3 \%$ & \\
\hline South & $53.1 \%$ & $46.2 \%$ & $38.3 \%$ & \\
\hline West & $7.6 \%$ & $7.2 \%$ & $10.3 \%$ & \\
\hline Hospital Size & & & & \multirow[t]{4}{*}{$<0.001$} \\
\hline Small & $10.1 \%$ & $10.5 \%$ & $11.8 \%$ & \\
\hline Medium & $24.2 \%$ & $22.5 \%$ & $20.8 \%$ & \\
\hline Large & $65.7 \%$ & $66.9 \%$ & $67.4 \%$ & \\
\hline $\begin{array}{l}\text { Hospital Location/ teaching } \\
\text { Status }\end{array}$ & & & & \multirow[t]{4}{*}{$<0.001$} \\
\hline Rural & $6.1 \%$ & $6.1 \%$ & $5.7 \%$ & \\
\hline Urban non-teaching & $37.7 \%$ & $36.1 \%$ & $32.1 \%$ & \\
\hline Teaching & $56.2 \%$ & $57.8 \%$ & $62.2 \%$ & \\
\hline Elective admission & $26 \%$ & $19.8 \%$ & $18.4 \%$ & $<0.001$ \\
\hline Weekend Admission & $16.6 \%$ & $18.1 \%$ & $20.2 \%$ & $<0.001$ \\
\hline Median ZIP income, quartile & & & & \multirow[t]{3}{*}{$<0.001$} \\
\hline $1 \mathrm{st}$ & $25.6 \%$ & $20.9 \%$ & $19.6 \%$ & \\
\hline 2nd & $26 \%$ & $23.9 \%$ & $24.4 \%$ & \\
\hline
\end{tabular}




\begin{tabular}{|c|c|c|c|c|}
\hline $3 r d$ & $24.6 \%$ & $28.1 \%$ & $27.3 \%$ & \\
\hline 4th & $23.8 \%$ & $27.1 \%$ & $28.7 \%$ & \\
\hline Expected Primary Payer & & & & \multirow[t]{7}{*}{$<0.001$} \\
\hline Medicare & $51.1 \%$ & $52.8 \%$ & $51.9 \%$ & \\
\hline Medicaid & $5.9 \%$ & $4.3 \%$ & $3.4 \%$ & \\
\hline Private & $34.6 \%$ & $37.1 \%$ & $40.2 \%$ & \\
\hline Uninsured & $5.1 \%$ & $3.1 \%$ & $2.2 \%$ & \\
\hline No charge & $0.5 \%$ & $0.3 \%$ & $0.3 \%$ & \\
\hline Other & $2.8 \%$ & $2.3 \%$ & $2 \%$ & \\
\hline Single vessel PCI & $47.9 \%$ & $54.1 \%$ & $52.4 \%$ & $<0.001$ \\
\hline Bifurcation stenting & $1.5 \%$ & $1.5 \%$ & $2.2 \%$ & $<0.001$ \\
\hline \multicolumn{4}{|l|}{ Stent Type } & \multirow[t]{5}{*}{$<0.001$} \\
\hline Bare Metal & $20.8 \%$ & $25.8 \%$ & $28.7 \%$ & \\
\hline Drug Eluting & $72 \%$ & $67.1 \%$ & $63.4 \%$ & \\
\hline Both & $1.9 \%$ & $1.7 \%$ & $2 \%$ & \\
\hline Unknown & $9.1 \%$ & $8.8 \%$ & $9.9 \%$ & \\
\hline Use of assist device or IABP & $3.3 \%$ & $3.1 \%$ & $3.7 \%$ & 0.040 \\
\hline Fractional flow reserve & $0.7 \%$ & $1.1 \%$ & $0.8 \%$ & $<0.001$ \\
\hline Intravascular ultrasound & $3.9 \%$ & $4 \%$ & $4.3 \%$ & 0.189 \\
\hline $\begin{array}{l}\text { Optical Coherence } \\
\text { Tomography }\end{array}$ & $0.1 \%$ & $<0.1 \%$ & $0.1 \%$ & 0.052 \\
\hline PCI indication: & & & & $<0.001$ \\
\hline Stable Angina Pectoris & $30.8 \%$ & $23.2 \%$ & $22.8 \%$ & \\
\hline STEMI & $23.6 \%$ & $24.4 \%$ & $25.6 \%$ & \\
\hline NSTEMI & $24.1 \%$ & $27 \%$ & $29.2 \%$ & \\
\hline Unstable Angina Pectoris & $21.5 \%$ & $25.4 \%$ & $22.4 \%$ & \\
\hline Cardiogenic Shock & $3 \%$ & $2.8 \%$ & $2.8 \%$ & 0.201 \\
\hline $\begin{array}{l}\text { Length of stay, (days), } \\
\text { median (IQR) }\end{array}$ & $2(1,4)$ & $2(1,4)$ & $2(1,4)$ & 0.052 \\
\hline $\begin{array}{l}\text { Total charge, } \$ \text {, median } \\
\text { (IQR) }\end{array}$ & $\begin{array}{c}45,372(32,133, \\
68,818)\end{array}$ & $\begin{array}{c}45,290 \\
(32,938, \\
65,459)\end{array}$ & $\begin{array}{c}48,175 \\
(34,269, \\
70,834)\end{array}$ & $<0.001$ \\
\hline
\end{tabular}




\begin{tabular}{|c|c|c|c|c|}
\hline Previous MI & $10.4 \%$ & $9.5 \%$ & $7.7 \%$ & $<0.001$ \\
\hline Previous PCI & $13.7 \%$ & $11.2 \%$ & $12.2 \%$ & $<0.001$ \\
\hline Previous CABG & $8.4 \%$ & $6.7 \%$ & $7.2 \%$ & $<0.001$ \\
\hline Previous CVA & $2.5 \%$ & $2 \%$ & $2 \%$ & $<0.001$ \\
\hline Heart failure & $14.7 \%$ & $12.5 \%$ & $13 \%$ & $<0.001$ \\
\hline Valvular disease & $0.3 \%$ & $0.2 \%$ & $0.3 \%$ & 0.367 \\
\hline Atrial fibrillation/flutter & $10.5 \%$ & $11 \%$ & $12.4 \%$ & $<0.001$ \\
\hline Hypertension & $69.9 \%$ & $68.4 \%$ & $68 \%$ & $<0.001$ \\
\hline Hyperlipidaemia & $59.9 \%$ & $51 \%$ & $56.1 \%$ & $<0.001$ \\
\hline Diabetes Mellitus & $33.7 \%$ & $26.3 \%$ & $28.5 \%$ & $<0.001$ \\
\hline Smoker & $19.3 \%$ & $19 \%$ & $9 \%$ & $<0.001$ \\
\hline Peripheral vascular disorder & $10.5 \%$ & $9.8 \%$ & 10.1 & 0.039 \\
\hline Renal Failure & $9.9 \%$ & $9.3 \%$ & $9.8 \%$ & 0.104 \\
\hline Chronic Pulmonary disease & $15.7 \%$ & $18.8 \%$ & $15.5 \%$ & $<0.001$ \\
\hline Obesity & $12.7 \%$ & $10.2 \%$ & $12.3 \%$ & $<0.001$ \\
\hline Previous bowel resection & $0.1 \%$ & $1.2 \%$ & $0.4 \%$ & $<0.001$ \\
\hline Fluid \& electrolyte disorders & $9.7 \%$ & $13.2 \%$ & $11.3 \%$ & $<0.001$ \\
\hline Anaemia & $8.3 \%$ & $13.2 \%$ & $12.5 \%$ & $<0.001$ \\
\hline Hypothyroidism & $7.8 \%$ & $9.4 \%$ & $10.7 \%$ & $<0.001$ \\
\hline Thrombocytopenia & $1.4 \%$ & $1.6 \%$ & $2.2 \%$ & $<0.001$ \\
\hline Coagulopathy & $2.3 \%$ & $2.5 \%$ & $3.4 \%$ & $<0.001$ \\
\hline Depression & $5.5 \%$ & $9.4 \%$ & $7.4 \%$ & $<0.001$ \\
\hline Chronic Liver Disease & $0.9 \%$ & $1.6 \%$ & $1.7 \%$ & $<0.001$ \\
\hline Alcohol abuse & $2.1 \%$ & $1.8 \%$ & $1.7 \%$ & 0.010 \\
\hline Drug abuse & $1.4 \%$ & $1.7 \%$ & $0.7 \%$ & $<0.001$ \\
\hline AIDS & $0.1 \%$ & $0.1 \%$ & $<0.1 \%$ & 0.995 \\
\hline Other Neurological disorders & $3 \%$ & $4.6 \%$ & $2.7 \%$ & $<0.001$ \\
\hline Paralysis & $0.7 \%$ & $0.3 \%$ & $0.9 \%$ & $<0.001$ \\
\hline Psychoses & $1.4 \%$ & $2.5 \%$ & $1.5 \%$ & $<0.001$ \\
\hline $\begin{array}{l}\text { Pulmonary circulation } \\
\text { disorders }\end{array}$ & $0.2 \%$ & $0.3 \%$ & $0.3 \%$ & $<0.001$ \\
\hline
\end{tabular}




\begin{tabular}{|l|c|c|c|c|}
\hline $\begin{array}{l}\text { Peptic ulcer disease without } \\
\text { bleeding }\end{array}$ & $<0.1 \%$ & $<0.1 \%$ & $<0.1 \%$ & 0.129 \\
\hline Weight loss & $0.9 \%$ & $1.4 \%$ & $1.4 \%$ & $<0.001$ \\
\hline $\begin{array}{l}\text { Solid tumour without } \\
\text { metastasis }\end{array}$ & $0.9 \%$ & $1.1 \%$ & $1.5 \%$ & 0.001 \\
\hline Lymphoma & $0.3 \%$ & $0.3 \%$ & $0.5 \%$ & 0.038 \\
\hline Metastatic cancer & $0.3 \%$ & $0.4 \%$ & $0.5 \%$ & $<0.001$ \\
\hline
\end{tabular}


Table 2: In-hospital adverse events stratified by disease type.

\begin{tabular}{|c|c|c|c|c|c|}
\hline \multirow[t]{2}{*}{ Variable } & \multirow[t]{2}{*}{$\begin{array}{c}\text { No IBD } \\
(\mathrm{n}=6,670,383)\end{array}$} & \multicolumn{2}{|c|}{$\begin{array}{c}C D \\
(n=10,367)\end{array}$} & \multicolumn{2}{|c|}{$\begin{array}{c}\text { UC } \\
(n=8,543)\end{array}$} \\
\hline & & & $p$-value ${ }^{1}$ & & $p$-value ${ }^{1}$ \\
\hline $\mathrm{MACCE}^{2}$ & $4.3 \%$ & $3.1 \%$ & $<0.001$ & $3.6 \%$ & $<0.001$ \\
\hline Mortality & $1.7 \%$ & $1.5 \%$ & 0.216 & $0.9 \%$ & $<0.001$ \\
\hline Cardiac complications $^{3}$ & $1.2 \%$ & $0.6 \%$ & $<0.001$ & $1.3 \%$ & 0.220 \\
\hline Acute Stroke/TIA & $1.7 \%$ & $1.2 \%$ & $<0.001$ & $1.5 \%$ & 0.198 \\
\hline Vascular complications & $0.6 \%$ & $0.4 \%$ & 0.036 & $0.5 \%$ & 0.104 \\
\hline Major Bleeding & $1.2 \%$ & $2 \%$ & $<0.001$ & $1.9 \%$ & $<0.001$ \\
\hline GI Bleeding & $0.8 \%$ & $1.4 \%$ & $<0.001$ & $1.7 \%$ & $<0.001$ \\
\hline
\end{tabular}

1 Reference group is 'no IBD'.

2 composite of mortality, cardiac complication, and acute stroke/TIA.

3 composite of coronary dissection, pericardial effusion or hemopericardium and cardiac tamponade. 
All records taken from NiS database from 2004 - 2015

$\downarrow$
Identified records with a PCI
using ICD-9 codes including 0.66 ,

$36.01,36.02,36.05,36.06,36.07$

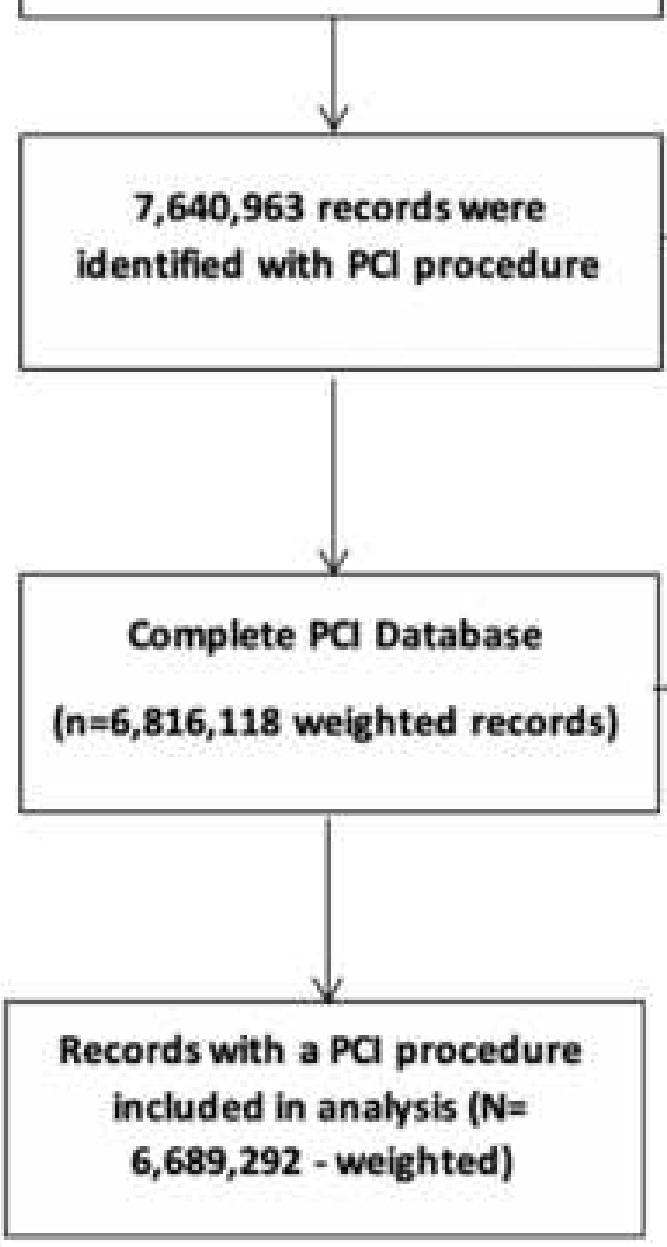

\section{Excluded due to missing Data $(n=824,845)$}

- Age: $n=270$.

- Gender: $\mathrm{n=582}$.

- Elective procedure: $n=22,623$.

- Weekend admission: $n=53$.

- Hospital location/teaching status: $n=805,413$.

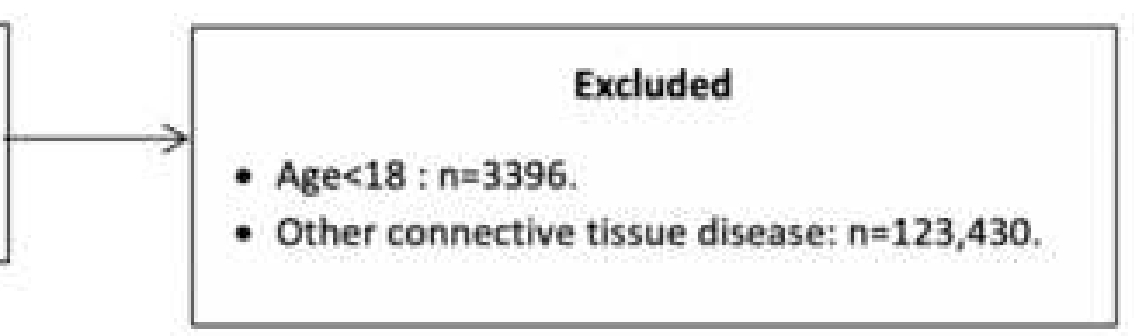




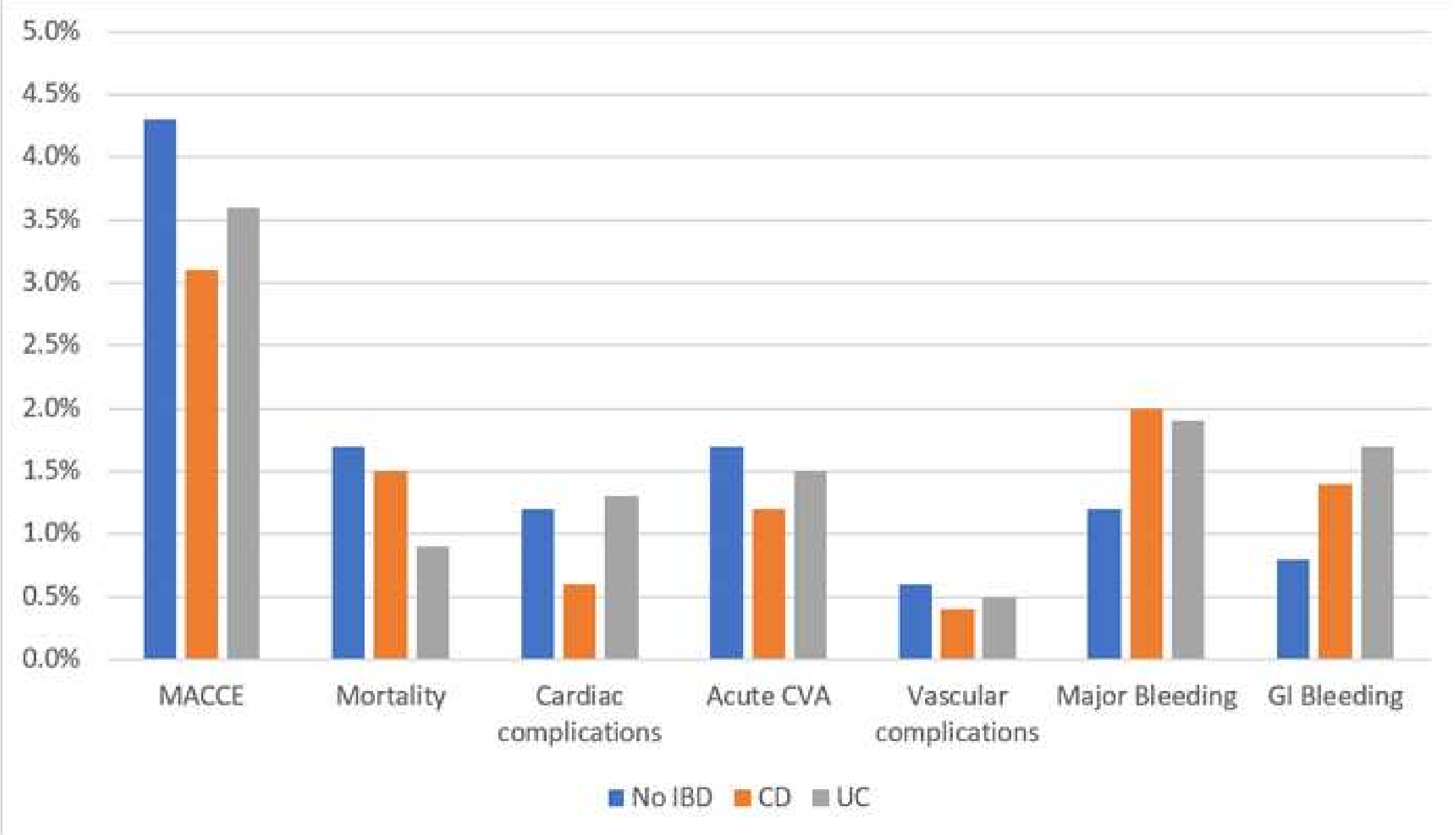




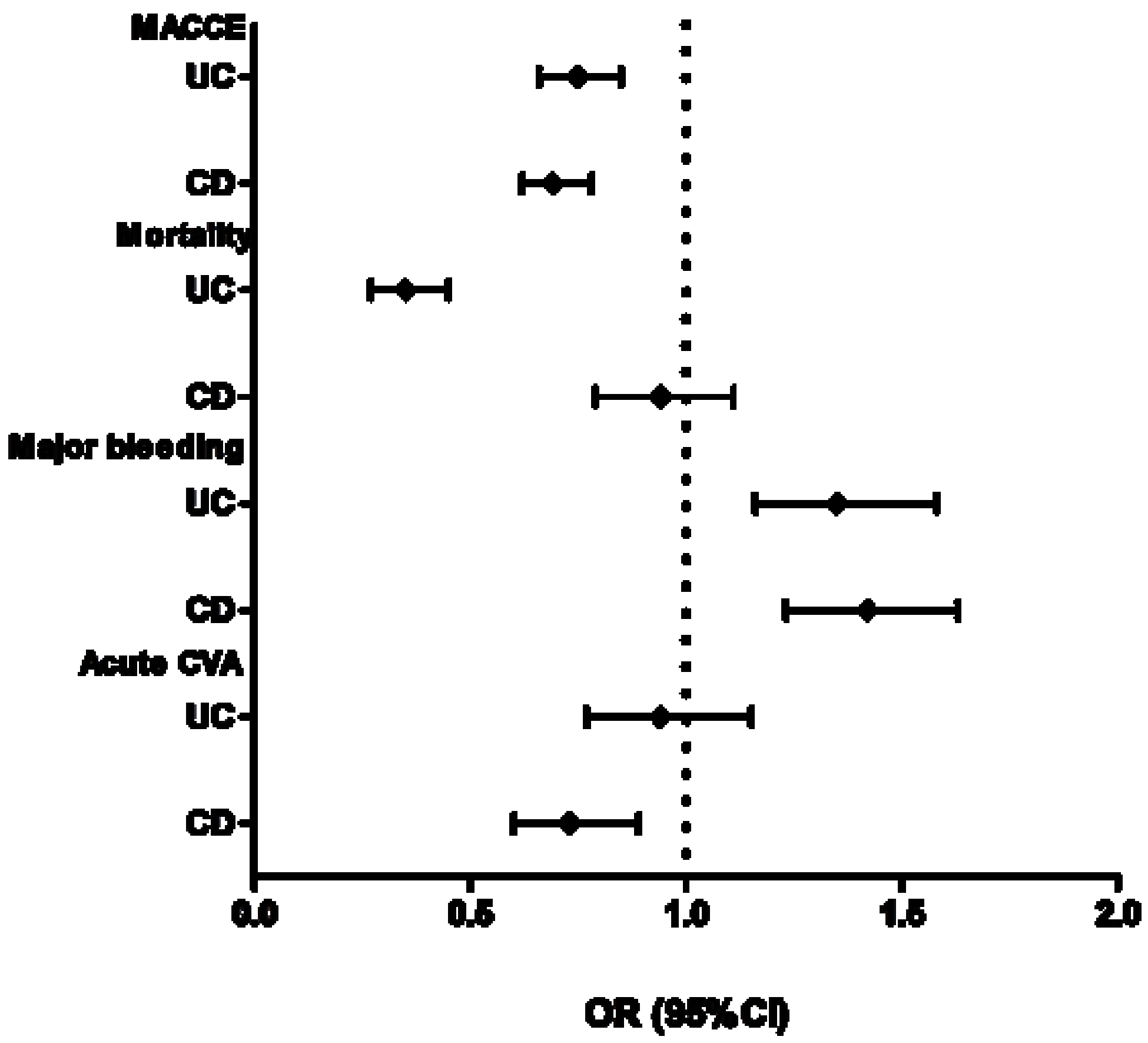


Electronic Supplementary Material (online publication only)

Click here to access/download Electronic Supplementary Material (online publication only)

Supplementary Table 1.docx 


\section{CRediT author statement}

Ofer Kobo- Conceptualization, methodology, Formal analysis, writing-original draft Mohamed O. Mohamed- Conceptualization, methodology, writing-original draft

Adam D Farmer- Writing - Review \& Editing

M Chadi Alraies- Writing - Review \& Editing

Tejas Patel ${ }^{-}$Writing - Review \& Editing

Kamal Sharma- Writing - Review \& Editing,

Jim Nolan` Writing - Review \& Editing,

Rodrigo Bagur- Writing - Review \& Editing

Ariel Roguin- Writing - Review \& Editing

Mamas A. Mamas- Conceptualization, methodology, Writing - Review \& Editing,

Supervision, Project Admistration 